\title{
BMJ Open Socioeconomic inequalities in suicide mortality in Barcelona during the economic crisis (2006-2016): a time trend study
}

\author{
Natalia López-Contreras, ${ }^{1,2}$ Maica Rodríguez-Sanz, ${ }^{1,3,4,5}$ Ana Novoa, ${ }^{2,5}$ \\ Carme Borrell, ${ }^{1,3,5,6}$ Jordi Medallo Muñiz, ${ }^{7}$ Mercè Gotsens ${ }^{2,3}$
}

To cite: López-Contreras N, Rodríguez-Sanz M, Novoa A, et al. Socioeconomic inequalities in suicide mortality in Barcelona during the economic crisis (2006-2016): a time trend study. BMJ Open 2019;9:e028267. doi:10.1136/ bmjopen-2018-028267

- Prepublication history and additional material for this paper are available online. To view these files, please visit the journal online (http://dx.doi. org/10.1136/bmjopen-2018028267).

Received 29 November 2018 Revised 17 July 2019 Accepted 22 July 2019
Check for updates

(C) Author(s) (or their employer(s)) 2019. Re-use permitted under CC BY-NC. No commercial re-use. See rights and permissions. Published by BMJ.

For numbered affiliations see end of article.

Correspondence to Natalia López-Contreras; ext_nlopez@aspb.cat

\section{ABSTRACT}

Objectives This study aimed to analyse trends in socioeconomic inequalities in suicide mortality in Barcelona before and after the start of the economic crisis that started at the end of 2008 , including both individual factors and contextual factors of the deceased's neighbourhood of residence.

Design This is a trend study of three time periods: preeconomic crisis (2006-2008), early crisis (2009-2012) and late crisis (2013-2016).

Setting Total Barcelona residents between 2006 and 2016 ( $\geq 25$ years of age) and death data derived from the Judicial Mortality Registry of Barcelona.

Participants 996 deaths by suicide between 2006 and 2016 were analysed.

Primary and secondary outcome measures The outcomes were age-standardised suicide mortality rates and the associations (relative and absolute risk) between suicide mortality and individual and contextual characteristics for the three time periods.

Results From 2006 to 2008, men with a lower educational level were more likely to commit suicide than better educated men (relative risk $(\mathrm{RR})=1.46 ; 95 \% \mathrm{Cl}$ 1.11 to 1.91). This difference disappeared after the onset of the crisis. We found no differences among women. From 2013 to 2016, suicide risk increased among men living in neighbourhoods with higher unemployment levels ( $R R=1.57 ; 95 \% \mathrm{Cl} 1.09$ to 2.25) and among women living in neighbourhoods with a higher proportion of elderly people living alone ( $\mathrm{RR}=2.13 ; 95 \% \mathrm{Cl} 1.15$ to 3.93 ). Conclusions We observed risks for suicide among men living in neighbourhoods of Barcelona with higher unemployment levels and among women living in neighbourhoods with a higher proportion of elderly people living alone. Inequalities in suicide mortality according to educational level tended to disappear during the crisis among men. Thus, it is important to continue to monitor suicide determinants especially in times of economic crisis.

\section{INTRODUCTION}

Suicide is a major problem for public health. Suicide rates are often considered as a measure of a country's emotional well-being, ${ }^{1}$ especially in times of economic crisis such as
Strengths and limitations of this study

- Data were obtained from the Judicial Mortality Registry of Barcelona, which is up-to-date and prevents under-reporting of suicide as a cause of death.

- The analysis includes socioeconomic variables, both social and material, which proved to be very useful for suicide surveillance during the economic crisis.

- The low number of suicides in Barcelona, especially among women, hindered detection of significant associations and stratified analyses.

- A change in Barcelona's territorial divisions in 2009 hampered collection of contextual data for the time periods studied.

that experienced by western countries since 2008.

Like other health issues, suicide is influenced by various social determinants. We have summarised these determinants in a conceptual framework (figure 1), drawing on information previously presented by the Commission on Reducing Social Inequalities in Spain (Comisión para Reducir las Desigualdades Sociales en Salud en España). ${ }^{2}$ These determinants can be classified as either structural or intermediary. In terms of structural determinants, both the socioeconomic and the political features of a country can influence suicide mortality rates. Because macroeconomic and welfare state policies depend on the government in power, as well as on political traditions, austerity measures and reduced social benefits implemented during an economic crisis tend to increase suicide rates. ${ }^{3}$ In addition, social cohesion is known to be a protective factor against suicide, with previous studies showing that high social trust (as part of social capital) ${ }^{45}$ and high electoral participation (voter turnout) are associated with fewer suicides. ${ }^{67}$ Intermediary determinants, which are very important for suicide 


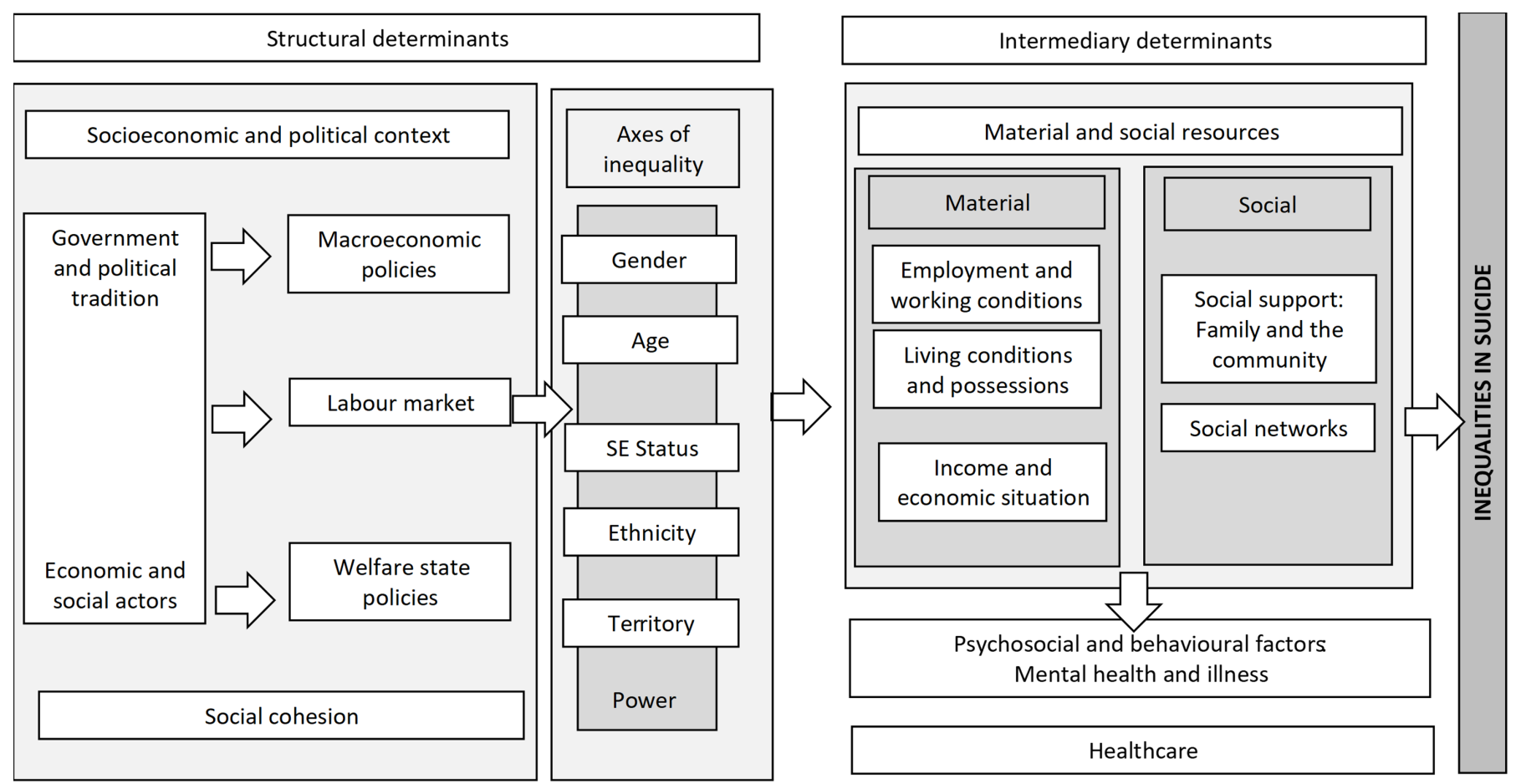

Figure 1 Conceptual framework of the determinants of inequalities in suicide. This figure was adapted from the conceptual framework of the determinants of health inequalities developed by the Commission on Reducing Social Inequalities in Spain (Comisión para Reducir las Desiguald ades Sociales en Salud en España). ${ }^{2}$

risk, can be divided into material and social resources. Higher suicide rates are known to occur in areas with greater unemployment ${ }^{8}$ or less social or family support, as measured by the proportion of people living alone. ${ }^{9}$ Moreover, mental illness is also a risk factor for suicide and is involved in a high percentage of cases. ${ }^{10}$ Because all these determinants change according to axes of inequality, they influence suicide in a non-uniform manner. For example, particular groups are more affected, such as men, ${ }^{11}$ both young and old adults, ${ }^{8} 12$ and individuals with a poorer socioeconomic position-whether it be in terms of education, income or occupation. ${ }^{12-16}$

While many studies have analysed trends in suicide mortality during economic crises, ${ }^{17}$ few have examined concurrent trends in socioeconomic inequalities in suicide mortality during these periods. These latter studies have observed greater suicide mortality among men from a manual social class ${ }^{18}$ or with a lower level of education. ${ }^{19}$ However, a more recent study conducted in Spain showed that the trend in educational inequalities in suicide mortality was stable among men before and during the latest economic recession. ${ }^{20}$ Thus, further studies are required to investigate the impact of the economic crisis on social inequalities in suicide mortality, using updated data after the economic crisis by gender and taking into account many aspects presented in our conceptual framework.

The objective of our study was to analyse trends in socioeconomic inequalities in suicide mortality in Barcelona before and after the onset of the recent economic crisis, including both individual and contextual factors of the deceased's neighbourhood of residence.

\section{METHODS \\ Design and information sources}

We performed a trend study of the period 2006-2016, including all Barcelona residents aged $\geq 25$ years. We gathered information from the Judicial Mortality Registry (maintained by the Catalan Institute of Legal Medicine and Forensic Sciences and the Municipal Population Census of Barcelona) and the Drug Addiction Information System maintained by Barcelona Public Health Agency, the city's Municipal Population Census and the Department of Statistics of Barcelona City Council.

\section{Variables and indicators}

The dependent variable was suicide mortality: codes X60-X84 of the International Classification of Diseases 10 th revision.

Individual explanatory variables were (1) educational level ('primary education or lower' or 'secondary education or higher') as an indicator of individual socioeconomic position, (2) country of birth ('Spain' or 'elsewhere'), (3) neighbourhood of residence and (4) year of death ('pre-economic crisis' (2006-2008), 'early crisis' (2009-2012) or 'late crisis' (2013-2016)). We used gender as a stratification variable and age as an adjustment variable. For all independent variables, the proportion of missing data was $<11 \%$. An analysis of missing data was carried out. We observed a random distribution of 
the independent variables among people older than 25 years, with the education level and the address assigned, and those who did not have this information.

Contextual explanatory variables related to the neighbourhood of residence were chosen based on the conceptual framework (figure 1): (1) level of unemployment (in terms of the average annual percentage of individuals enrolled in the Employment Service of Catalonia) among individuals aged 16-64 years in 2011, (2) the percentage of individuals aged $\geq 65$ years who lived alone in 2008 , (3) the percentage of individuals who participated in general elections in 2011 and (4) the index of high-risk drug use in 2015 (a synthetic index that evaluates drug use by combining five indicators: the incidence of treatment initiation for substance abuse, the incidence of overdose-induced mortality according to place of residence and place of death, the incidence of drug-related hospital emergencies and the incidence of syringes found in the streets). All the contextual explanatory variables related to the neighbourhood of residence were categorised in quartiles.

\section{Patient and public involvement}

This study analysed the Judicial Mortality Registry database. Therefore, we did not inform participants of the research question, outcome measures or results. No participants were involved in the study, including its design, recruitment or conduct. There was no patient adviser for the contributors' statement.

\section{Data analysis}

All analyses were carried out using the STATA V.13 programme and were stratified by gender.

First, we directly calculated age-standardised suicide mortality rates (ASMRs) according to gender, educational level and country of birth for each time period using the study population described above. And we conducted Poisson regression models adjusted for age using the variable period in continuous to estimate trends across time.

Second, we calculated ASMRs for the neighbourhoods represented in the quartile maps. We calculated the Spearman correlation between suicide mortality rates and the contextual variables.

Finally, due to the hierarchical structure of the data, we conducted a multilevel analysis by fitting a Poisson regression model with a random neighbourhood effect (random constant) to control for variability between neighbourhoods. As we found no significant variability, we decided to fit Poisson regression models including individual and contextual neighbourhood variables to estimate relative risk (RR) and absolute risk (AR) of suicide mortality and 95\% CI. Initially, we fitted a model (model 1) containing the individual variables and a term representing the interaction between educational level and time period. In subsequent models, we added a different contextual variable and a term representing the interaction between this variable and the time period, thereby generating four different models (model 2: \% unemployment; model 3\% elderly living alone; model 4: \% voter turnout; model 5 : drug use index). We evaluated the model fit by using the deviance and likelihood ratio between nested models ( $p$ value). We then estimated the interaction of contextual explanatory variables and time periods for each variable using the time period as a categorical variable in the model (presenting the $\mathrm{p}$ value of the interaction).

\section{RESULTS}

Between 2006 and 2016, 1178 residents of Barcelona aged $>25$ years committed suicide. In 996 of these individuals, we were able to retrieve information regarding their educational levels and neighbourhoods of residence through the Judicial Mortality Registry. These individuals formed the final study sample and constituted the target population for the statistical analyses. In total, $69.1 \%$ $(\mathrm{n}=688)$ of the study population were men.

The ASMR decreased among men $(\mathrm{p}=0.022)$ during the study period (table 1), while rates among women remained stable. In all three periods, the suicide mortality rate was higher among men than women. Suicide mortality rate was higher among men born in Spain compared with those born elsewhere. This difference decreased with time because rates among men born outside of Spain increased during the last period of the study ( $p=0.019$ ). By educational level, the rate of suicide between 2006 and 2008 was higher among men with a lower level of education. However, in this group of men, the rate decreased in the other time periods $(\mathrm{p}=0.002)$, while men with a higher educational level had stable rate over time.

Among women, suicide rates were highest during the pre-crisis period (2006-2008) among those born outside Spain, but the number of suicides was very low in this group. In this group of women, the rate decreased in the other time periods $(\mathrm{p}=0.025)$, while the rate was higher for women born in Spain. By educational level, women with a higher level of education had higher suicide mortality rates in all three periods, and this rate remained stable over time among in this group, as well as in women with a lower level of education.

Analysis of the distribution of suicide mortality in the various neighbourhoods of Barcelona (figure 2) revealed no clear patterns for men or women in any of the time periods. Table 2 shows the Spearman correlations between suicide mortality rates and the contextual explanatory variables, and shows that suicide mortality in men was positively correlated with the index of high-risk drug use, and negatively correlated with voter turnout. In contrast, suicide mortality among women was positively correlated with voter turnout and with the proportion of elderly people living alone. Unemployment was not significantly correlated with the suicide rate in either men or women, although the correlation in men tended to be opposite to that in women. Online supplementary figure 1 shows the distribution in quartiles across the neighbourhoods of Barcelona of average annual percentage of unemployed 


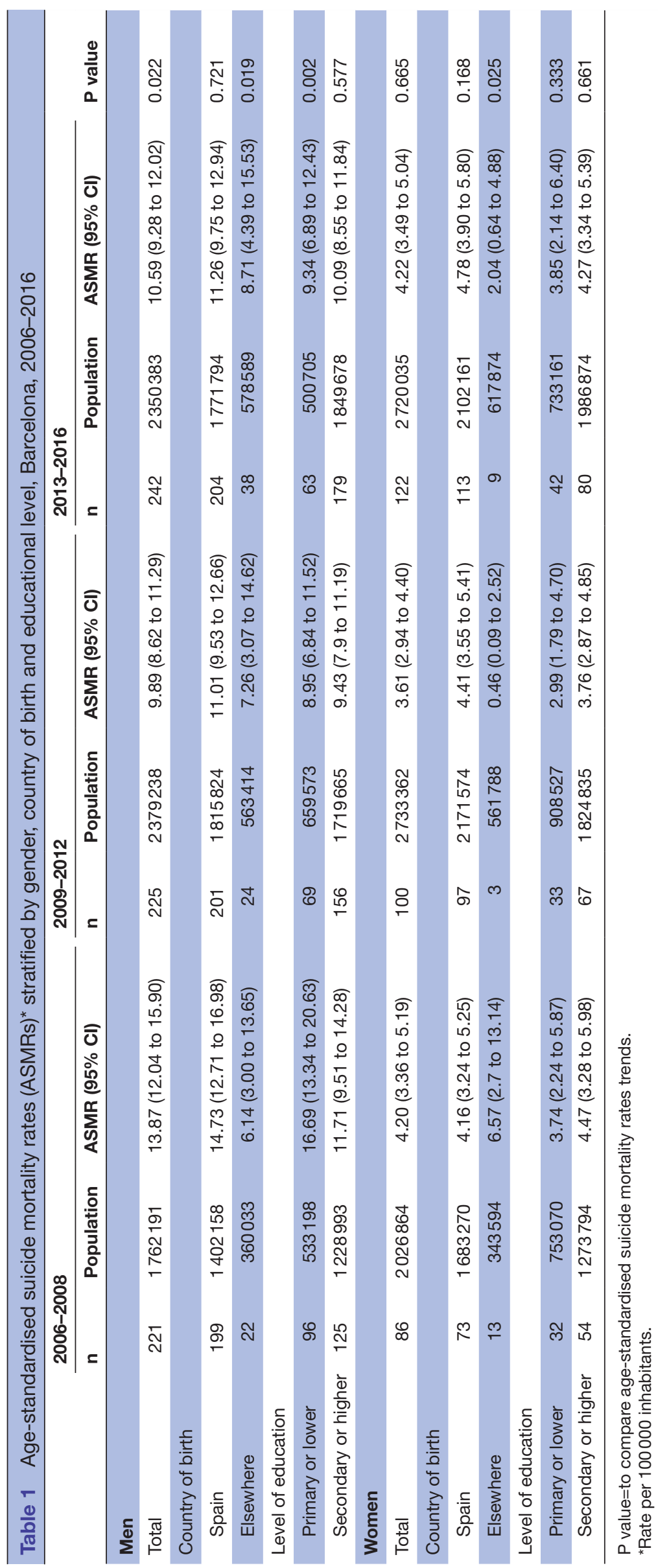


A Suicide Rates in Men Barcelona, 2006-2008

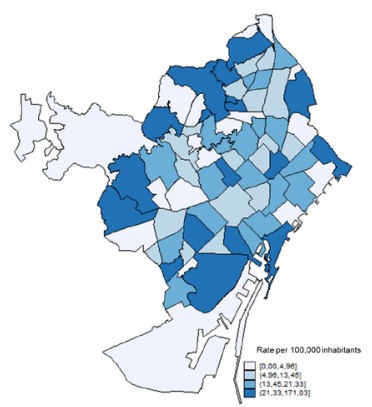

D suicide Rates in Women Barcelona, 2006-2008

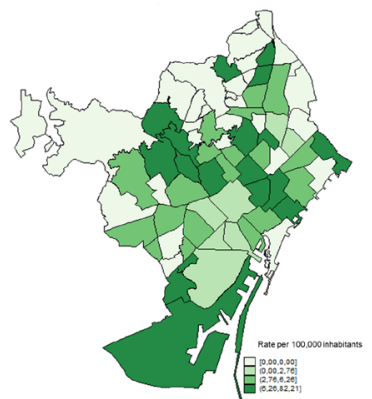

B

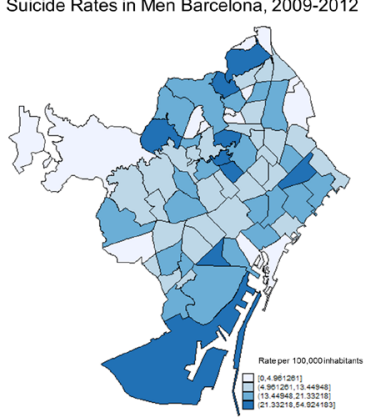

C Suicide Rates in Men Barcelona, 2013-2016
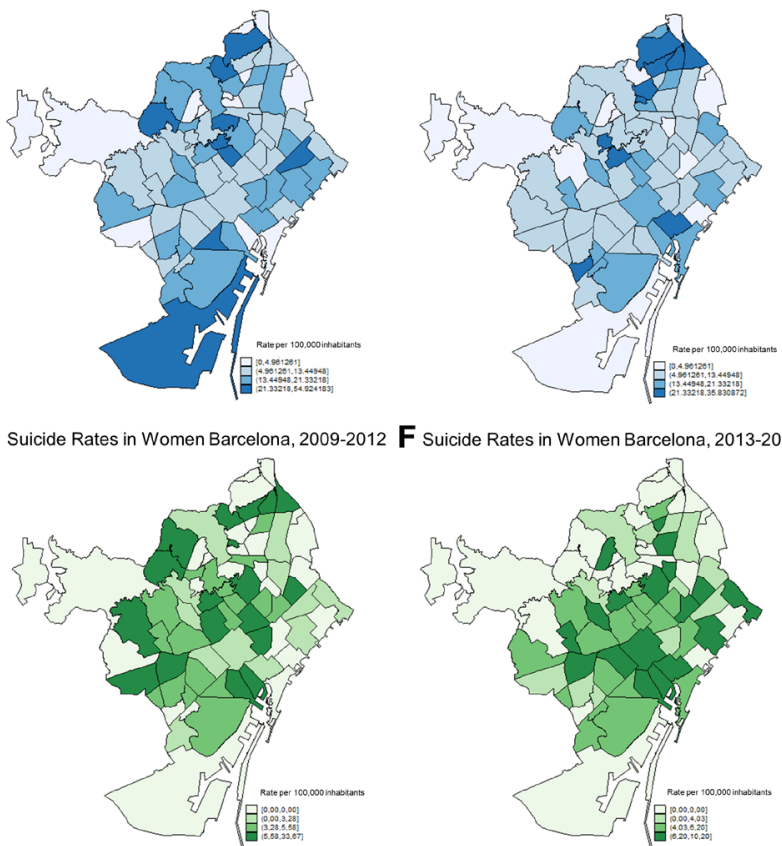

Figure 2 Distribution in quartiles of age-standardised mortality rates in men during the periods (A) 2006-2008, (B) 2009-2012, (C) 2013-2016, and in women during the periods (D) 2006-2008, (E) 2009-2012, (F) 2013-2016.

individuals for 2011, the percentage of people aged $>65$ years living alone in 2008, the percentage of participation in the general election in 2011 and the index of high-risk drug use in 2015.

Table 3 summarises the associations between suicide mortality in men and the individual and contextual characteristics for the three time periods studied. During the pre-crisis period, less well-educated men were more likely to commit suicide than those with a higher level of education ( $\mathrm{RR}=1.46 ; 95 \%$ CI 1.11 to 1.91 ), whereas the level of risk in each group was similar during the early $(\mathrm{RR}=0.96 ; 95 \%$ CI 0.72 to 1.28$)$ and late $(\mathrm{RR}=1.04 ; 95 \%$ CI 0.77 to 1.40 ) crisis periods. While men living in areas with high unemployment (third quartile) had greater risk of suicide during the early crisis ( $\mathrm{RR}=1.56 ; 95 \% \mathrm{CI}$ 1.08 to 2.25), those living in areas with the highest unemployment had greater risk during the late crisis period ( $\mathrm{RR}=1.57$; $95 \%$ CI 1.09 to 2.25). During the pre-crisis period, men living in neighbourhoods in the first quartile of voter turned out to be more likely to commit suicide ( $R R=1.68 ; 95 \%$ CI 1.12 to 2.52). Nonetheless, men living in neighbourhoods in the third quartile areas were less likely to commit suicide during the late crisis period ( $\mathrm{RR}=0.69 ; 95 \% \mathrm{CI} 0.49$ to 0.98 ), with significant variation in the RR over time. In addition, the index of high-risk drug use was a risk factor during the pre-crisis period among men living in fourth quartile neighbourhoods ( $\mathrm{RR}=1.53$; $95 \% \mathrm{CI} 1.04$ to 2.24 ), and in the early

Table 2 Spearman correlations between suicide mortality and the contextual variables during the three time periods, Barcelona, 2006-2016

\begin{tabular}{lccc}
\hline & ASMR 2006-2008 & ASMR 2009-2012 & ASMR 2013-2016 \\
\hline Men & & & 0.11 \\
\hline \% unemployment, 2011 & 0.01 & 0.02 & 0.12 \\
\hline \% elderly people living alone, 2008 & 0.10 & 0.02 & $-0.28^{*}$ \\
\hline \%oter turnout, 2011 & -0.20 & 0.02 & $0.25^{*}$ \\
\hline Index of high-risk drug use, 2015 & 0.13 & & -0.19 \\
Women & & -0.12 & $0.39^{*}$ \\
\hline \% unemployment, 2011 & -0.12 & 0.16 & $0.23^{*}$ \\
\hline \% voter turnout, 2011 & $0.26^{*}$ & 0.02 & -0.14 \\
\hline Index of high-risk drug use, 2015 & 0.19 & -0.04 & \\
\hline
\end{tabular}

*Significant correlation, $\mathrm{p}<0.05$.

ASMR, age-standardised suicide mortality rate. 


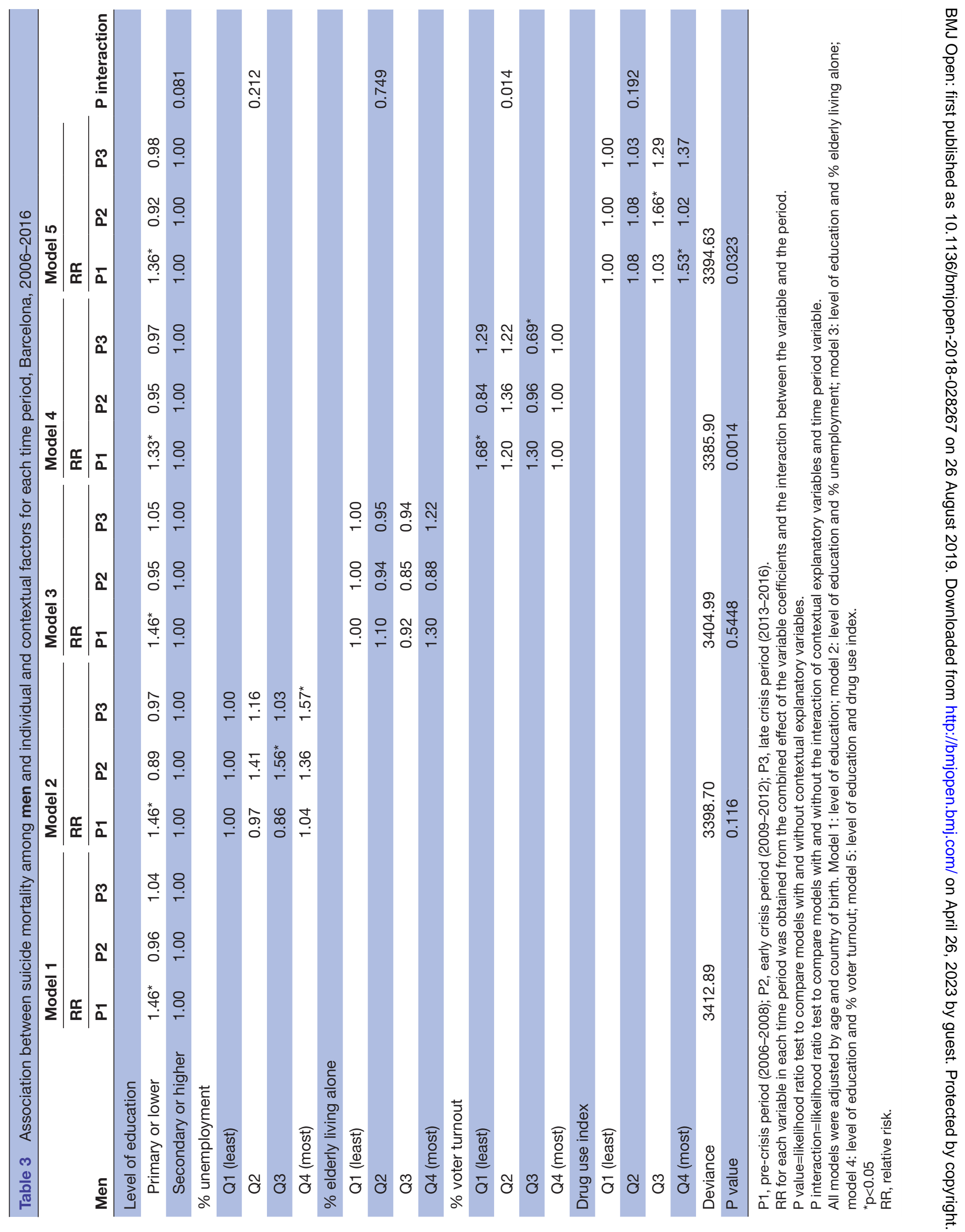


crisis period among those living in third quartile neighbourhoods ( $\mathrm{RR}=1.66$ : $95 \%$ CI 1.16 to 2.37 ).

Table 4 summarises the associations between suicide mortality in women and the individual and contextual characteristics for the three time periods studied. Educational level showed no statistically significant differences in suicide risk for any of the periods. In contrast, unemployment proved to be protective against suicide during the late crisis among women living in neighbourhoods in the third quartile of unemployment ( $\mathrm{RR}=0.48 ; 95 \%$ CI 0.27 to 0.84 ). Finally, women living in neighbourhoods with the highest proportion of elderly people living alone were generally more likely to commit suicide during the late crisis period ( $\mathrm{RR}=2.13$; $95 \%$ CI 1.15 to 3.93 ), although this risk did not vary significantly over time.

In general, the results obtained from ARs have the same pattern as those observed for the RRs in both men and women. In men, the AR decreases in those with lower levels of education and increases in men living in neighbourhoods with higher unemployment. In women, the AR increases in women who live in neighbourhoods with more elderly people living alone (online supplementary table 1).

\section{DISCUSSION}

In this study, we analysed trends in socioeconomic inequalities in suicide mortality in Barcelona. We found that after the onset of the economic crisis, inequalities in suicide rates by educational level tended to disappear in men, while suicide risk tended to increase among men living in neighbourhoods with higher unemployment. Among women, we found no inequalities by educational level, but observed higher suicide risk in the late crisis period among those living in neighbourhoods with a higher proportion of elderly people living alone.

Several studies have reported an association between suicide mortality and lower educational levels, ${ }^{12-14}$ but few have evaluated the late effect of economic crises. Studies in the $\mathrm{USA}^{21}$ and Asian countries ${ }^{19}$ found that inequality by educational level remained stable or even increased during economic recession. This contrasts with our results in that we found that suicide mortality decreased among men with a lower educational level and remained stable among men with a higher level of education. This suggests that the economic crisis in Barcelona has had a greater effect on men with a socioeconomic advantage, possibly because labour market restructuring created additional work-related stress and a feeling of job insecurity. In such a scenario, men with greater responsibilities could experience a more negative response and a decline in mental health. ${ }^{22}$ This notion is supported by the results of a Norwegian study ${ }^{23}$ reporting that suicide rates were higher among women with a higher level of education.

There is abundant evidence on the association between unemployment levels and suicide, especially during times of economic crisis. ${ }^{824}{ }^{25}$ Consistent with this evidence, we found that during the early (2009-2012) and late
(2013-2016) crisis periods, men living in areas with higher unemployment were more likely to commit suicide. In women, we found the opposite, with those living in neighbourhoods with high unemployment being less likely to commit suicide.

It is widely accepted that poor mental health is associated with suicide mortality. ${ }^{10}$ During the economic crisis in Spain, men experienced a general deterioration in mental health, ${ }^{26}$ especially those from lower socioeconomic classes. We observed a general correlation between suicide and the indicator for substance consumption, although we did not have access to the relevant individual information to properly support this assertion, so it may be susceptible to ecological fallacy. More specifically, we found that men living in neighbourhoods with problematic drug consumption had a higher risk of suicide (although the statistical significance of this factor decreased in the late crisis period).

The material and social factors that influence suicide mortality appear to differ between men and women, which may be because traditional gender roles create more pressure on men in terms of income and unemployment. In contrast, job loss among women is culturally more accepted since women typically find psychological compensation in their family role. ${ }^{27}$ According to studies on masculinity, this could also be associated with the fact that men are less likely to express their feelings and seek support in social networks when they need help concerning their mental health. ${ }^{28}$ In contrast, the increased risk of suicide among women may be likely due to alterations in social factors than to alterations in material factors. This is similar to a study conducted in Denmark $^{29}$ and in our study, in that we observed a higher suicide risk among women living in neighbourhoods with more elderly people living alone.

One of the limitations of our study is its low statistical power due to the small number of suicides in Barcelona, especially among women, which made it impossible to detect significant associations and to stratify the analyses by other variables such as age. It was also fairly difficult to obtain contextual data for the time periods studied because Barcelona underwent a change in its territorial divisions in 2009. Nonetheless, we were able to collect indicators for most determinants that are relevant for social inequalities in suicide.

The main strength of our study is that this study offers a conceptual framework that presents the social determinants most commonly related to suicide. It also offers an analysis by gender, which is relevant taking into account the difference in the risk factors for each gender. On the other hand, we used data from the Judicial Mortality Registry of Barcelona, which is not only more up-to-date than the Mortality Registry but also avoids under-reporting suicide as a cause of death. ${ }^{30}$ Furthermore, this registry allowed us to analyse social inequalities because it includes socioeconomic variables (educational level, country of birth and neighbourhood of residence), and was thus very useful for suicide surveillance during 


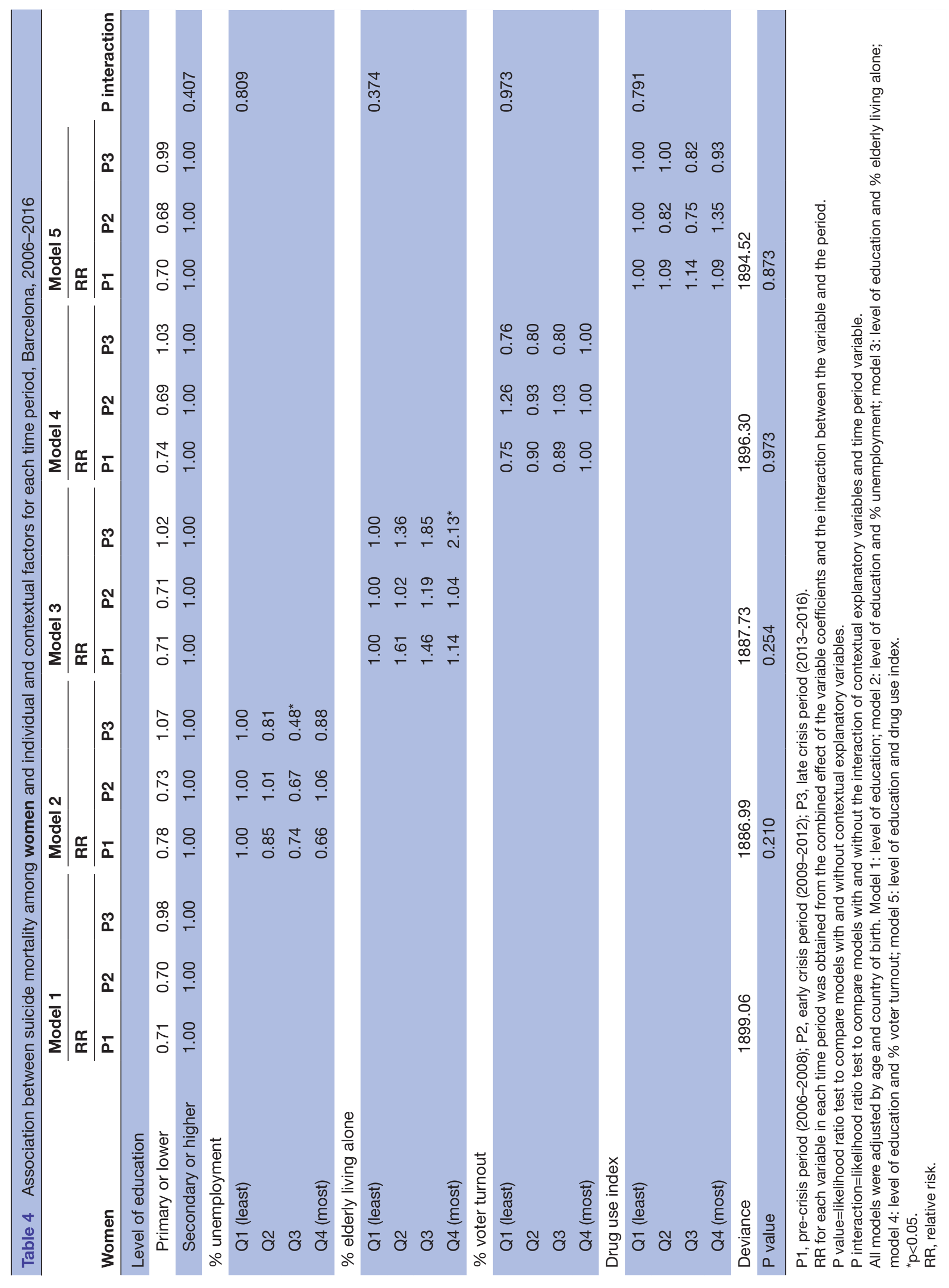

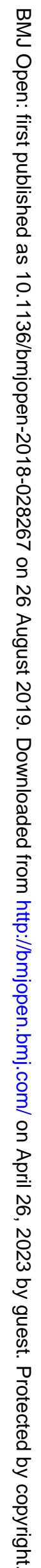


the economic crisis. Likewise, the records to obtain the contextual variables have a tradition of being of good quality and provide information at a small area level, which is not always available for this type of study. Similarly, while most previous studies only analysed variables related to material deprivation in suicide mortality, we evaluated both social and material contextual indicators.

In conclusion, we have shown that inequalities in suicide mortality by educational level among men tended to disappear during the crisis, although men living in neighbourhoods with higher unemployment may be more likely to commit suicide. In contrast, we found no association between suicide and educational level in women, but suicide might be more likely in women living in neighbourhoods with a higher number of elderly people living alone. Future studies should analyse the socioeconomic inequalities of suicide and further explore the causes of gender differences in this phenomenon. Since suicide is the endpoint of a process that can be treated previously at the population level, it is also important to continue monitoring its social determinants, especially during periods of economic crisis. This could be accomplished by establishing alliances with health centres that deal with cases of attempted suicide. In this way, we could gain further insight into the phenomenon and develop better strategies to improve the living conditions of people and prevent unnecessary deaths.

\section{Author affiliations}

${ }^{1}$ Department of Experimental and Health Sciences, Pompeu Fabra University, Barcelona, Spain

${ }^{2}$ Servei de Sistemes d'Informació Sanitària, Agència de Salut Pública de Barcelona, Barcelona, Spain

${ }^{3}$ Centro de Investigación Biomédica en Red de Epidemiología y Salud Pública (CIBERESP), Madrid, Spain

${ }^{4}$ Àrea de Recerca, Docència i Comunicació, Agència de Salut Pública de Barcelona, Barcelona, Spain

Institut d'Investigació Biomèdica (IIB) de Sant Pau, Barcelona, Spain

${ }^{6}$ Gerència, Agència de Salut Pública de Barcelona, Barcelona, Spain

${ }^{7}$ Clinical Service, Catalonian Institute of Legal Medicine and Forensic Science,

Barcelona, Spain

Acknowledgements To María Dolores Martos Hinojosa for her invaluable collaboration codifying all the judicial deaths of the Registry of Judicial Mortality of Barcelona.To the people of the Institut de Medicina Legal i Ciències Forenses de Catalunya and Civil Registry of Barcelona who have made this study possible.

Contributors MRS and MG made substantial contributions to the conception and design of this study. NLC, MRS and MG performed data analysis. NLC, MRS, MG, $\mathrm{CB}$ and $\mathrm{AN}$ contributed to the interpretation of data. NLC was involved in drafting the manuscript, and MRS, MG, CB, AN and JM revised it critically for important intellectual content. All authors gave final approval of the version to be published.

Funding statement This research was partially supported by the CIBER Epidemiología y Salud Pública.

Map disclaimer The depiction of boundaries on the map(s) in this article do not imply the expression of any opinion whatsoever on the part of BMJ (or any member of its group) concerning the legal status of any country, territory, jurisdiction or area or of its authorities. The map(s) are provided without any warranty of any kind, either express or implied.

Competing interests None declared.

Patient consent for publication Not required.
Provenance and peer review Not commissioned; externally peer reviewed.

Data availability statement No data are available.

Open access This is an open access article distributed in accordance with the Creative Commons Attribution Non Commercial (CC BY-NC 4.0) license, which permits others to distribute, remix, adapt, build upon this work non-commercially, and license their derivative works on different terms, provided the original work is properly cited, appropriate credit is given, any changes made indicated, and the use is non-commercial. See: http://creativecommons.org/licenses/by-nc/4.0/.

\section{REFERENCES}

1. Okada K, Samreth S. A study on the socio-economic determinants of suicide: evidence from 13 European OECD countries. J Socio Econ 2013;45:78-85.

2. Borrell C, Malmusi D, Artazcoz L, et al. Propuesta de politicas e intervenciones para reducir las desigualdades sociales en salud en España: a proposal of policies and interventions to reduce social inequalities in health in Spain. Gac Sanit 2012;26:182-9.

3. Kentikelenis A, Karanikolos M, Reeves A, et al. Greece's health crisis: from austerity to denialism. The Lancet 2014;383:748-53.

4. Kelly BD, Davoren M, Mhaoláin AN, et al. Social capital and suicide in 11 european countries: an ecological analysis. Soc Psychiatry Psychiatr Epidemiol 2009;44:971-7.

5. Smith NDL, Kawachi I. State-level social capital and suicide mortality in the 50 U.S. states. Soc Sci Med 2014;120:269-77.

6. Whitley E, Gunnell D, Dorling D, et al. Ecological study of social fragmentation, poverty, and suicide. BMJ 1999;319:1034-7.

7. De Silva MJ, McKenzie K, Harpham T, et al. Social capital and mental illness: a systematic review. J Epidemiol Community Health 2005;59:619-27.

8. Milner A, McClure R, De Leo D. Socio-Economic determinants of suicide: an ecological analysis of 35 countries. Soc Psychiatry Psychiatr Epidemiol 2012;47:19-27.

9. Middleton N, Whitley E, Frankel S, et al. Suicide risk in small areas in England and Wales, 1991-1993. Soc Psychiatry Psychiatr Epidemiol 2004;39:45-52.

10. Turecki G, Brent DA. Suicide and suicidal behaviour. The Lancet 2016;387:1227-39.

11. World Health Organization. Preventing suicide: a global imperative. CMAJ 2014;143:609-10.

12. Kim $\mathrm{M}-\mathrm{H}$, Jung-Choi $\mathrm{K}$, Jun $\mathrm{H}-\mathrm{J}$, et al. Socioeconomic inequalities in suicidal ideation, parasuicides, and completed suicides in South Korea. Soc Sci Med 2010;70:1254-61.

13. Lorant V, Kunst AE, Huisman M, et al. Socio-Economic inequalities in suicide: a european comparative study. $\mathrm{Br} J$ Psychiatry 2005;187:49-54.

14. Li Z, Page A, Martin G, et al. Attributable risk of psychiatric and socio-economic factors for suicide from individual-level, populationbased studies: a systematic review. Soc Sci Med 2011;72:608-16.

15. Burrows S, Auger N, Gamache P, et al. Influence of social and material individual and area deprivation on suicide mortality among 2.7 million Canadians: a prospective study. BMC Public Health 2011;11:577.

16. Milner A, Spittal MJ, Pirkis J, et al. Suicide by occupation: systematic review and meta-analysis. Br J Psychiatry 2013;203:409-16.

17. Parmar D, Stavropoulou C, loannidis JPA. Health outcomes during the 2008 financial crisis in Europe: systematic literature review. BMJ 2016;354:i4588-4588. bmj BMJ.

18. Valkonen T. Changes in socioeconomic inequalities in mortality during an economic boom and recession among middle-aged men and women in Finland. Eur J Public Health 2000;10:274-80.

19. Lee WY, Khang Y-H, Noh M, et al. Trends in educational differentials in suicide mortality between 1993-2006 in Korea. Yonsei Med $J$ 2009;50:482-92.

20. Borrell C, Marí-Dell'Olmo M, Gotsens M, et al. Socioeconomic inequalities in suicide mortality before and after the economic recession in Spain. BMC Public Health 2017;17:1-8.

21. Harper S, Charters TJ, Strumpf EC, et al. Economic downturns and suicide mortality in the USA, 1980-2010: observational study. Int J Epidemiol 2015;44:956-66.

22. Chan $\mathrm{CH}$, Caine $\mathrm{ED}$, You $\mathrm{S}$, et al. Suicide rates among working-age adults in South Korea before and after the 2008 economic crisis. J Epidemiol Community Health 2014;68:246-52.

23. Strand $\mathrm{BH}$, Grøholt E-K, Steingrímsdóttir OA, et al. Educational inequalities in mortality over four decades in Norway: prospective study of middle aged men and women followed for cause specific mortality, 1960-2000. BMJ 2010;340. 
24. Catalano R, Goldman-Mellor S, Saxton $\mathrm{K}$, et al. The health effects of economic decline. Annu Rev Public Health 2011;32:431-50.

25. Baumbach A, Gulis G. Impact of financial crisis on selected health outcomes in Europe. Eur J Public Health 2014:24:399-403.

26. Bartoll X, Palència L, Malmusi $\mathrm{D}$, et al. The evolution of mental health in Spain during the economic crisis. Eur J Public Health 2014;24:415-8.

27. Artazcoz L, Benach J, Borrell C, et al. Unemployment and mental health: understanding the interactions among gender, family roles, and social class. Am J Public Health 2004;94:82-8.
28. Möller-Leimkühler AM. The gender gap in suicide and premature death or: why are men so vulnerable? Eur Arch Psychiatry Clin Neurosci 2003;253:1-8.

29. Agerbo E, Sterne JAC, Gunnell DJ. Combining individual and ecological data to determine compositional and contextual socioeconomic risk factors for suicide. Soc Sci Med 2007;64:451-61.

30. Gotsens M, Marí-Dell'Olmo M, Rodríguez-Sanz M, et al. Validación de la causa básica de defunción en las muertes que requieren intervención medicolegal. Rev Esp Salud Publica 2011;85:163-74. 